DOI: https://doi.org/10.47405/mjssh.v5i1.342

\begin{tabular}{|c|c|}
\hline & Malaysian Journal of Social Sciences and Humanities (MJSSH) \\
\hline Malaysian Journal of & Volume 5, Issue 1, January 2020 \\
\hline (MJ - sSH) & e-ISSN : 2504-8562 \\
\hline & $\begin{array}{l}\text { Journal home page: } \\
\text { www.msocialsciences.com }\end{array}$ \\
\hline
\end{tabular}

\title{
Konsep Penginstitusian Rumah Anak Yatim Miskin di Malaysia
}

\author{
Azlini Binti Chik ${ }^{1}$, Siti Hajar Binti Abdul Rauf', Lukman @ Zawawi Bin Mohamad \\ 1Fakulti Sains Sosial Gunaan, Universiti Sultan Zainal Abidin (UniSZA) \\ Correspondence: Azlini Binti Chik (azlinichik@gmail.com)
}

\begin{abstract}
Abstrak
Setiap negara mempunyai pandangan dan definisi yang berbeza mengenai rumah anak yatim miskin. Tujuan kajian ini dijalankan adalah untuk menjelaskan konsep rumah anak yatim miskin berdasarkan kaian-kajian lepas dan mencadangkan satu definisi yang jelas mengenai rumah anak yatim miskin di Malaysia berdasarkan Akta Pusat Jagaan 1993. Kertas kerja ini ini merupakan kertas konsep sahaja yang dibina berdasarkan kepada sorotan kajian, analisis dokumen ke atas kajian-kajian yang telah dilakukan oleh pengkaji-pengkaji sebelum ini. Data-data sekunder dikumpul dengan mengkaji kajankajian lepas dari dalam dan luar negara berkaitan dengan konsep rumah anak yatim miskin. Dapatan menunjukkan setiap negara mempunyai definisi yang berbeza terhadap rumah anak yatim miskin ini.
\end{abstract}

Kata kunci: penginstitusian, institutsi jagaan, rumah anak yatim, anak miskin

\section{The Concept of Institution of Orphanages in Malaysia}

\begin{abstract}
Each country has different views and definitions of orphanage. The purpose of this study was to clarify the concept of poor orphanage based on previous studies and propose a clear definition of orphanage in Malaysia under the Care Centers Act 1993. Secondary data were collected by studying past and present studies abroad related to the concept of orphanage. The findings show that each country has a different definition of this orphanage.
\end{abstract}

Keywords: institutionalisation, institutional care, orphanages, poor child

\section{Pengenalan}

Anak yatim adalah anak yang kematian bapa atau kedua-dua ibu bapa (Awang, Sayuti, Jamaluddin, \& Chong, 2004; Zhao et al., 2009; The Faith to Action Initiative, 2014; UNICEF, 2015; Bani Ismail, Hindawi, Awamleh, \& Alawamleh, 2018). Kanak-kanak yang kematian salah seorang ibu atau bapa diklasifikasikan sebagai 'single orphans' atau anak yatim; manakala kanak-kanak yang kematian kedua-dua ibu bapa diklasifikasikan sebagai "double orphans" atau anak yatim piatu (The Faith to Action Initiative, 2014; Monasch \& Boerma, 2004). 
Dari segi sejarah, perkembangan dalam penempatan kanak-kanak amat berkait rapat dengan penglibatan kerajaan kolonial Inggeris (Awang, Sayuti, Jamaluddin, \& Chong, 2004) di samping pengaruh agama Islam yang banyak membentuk amalan jagaan anak-anak yatim miskin khususnya di Semenanjung Malaysia sejak kurun ke 15 lagi (Fulcher \& Faizah, 2000). Kerajaan, Badan-Badan Bukan Kerajaan (NGO), badan-badan swasta mahupun badan-badan berasaskan keagamaan turut mengambil inisiatif dalam menyediakan rumah bagai anak-anak yatim miskin ini berlindung dan mendapat kemudahan-kemudahan pendidikan, kamahiran seperti mana anak-anak yang lain.

Bagi pihak kerajaan, tugas menempatkan anak-anak yatim miskin serta memberi kemudahan fizikal dan sosial kepada mereka adalah terletak di bawah bidang kuasa Jabatan Kebajikan Masyarakat (JKM). Pihak JKM akan menghulurkan sumbangan bagi membiayai perbelanjaan anak-anak yatim miskin, di samping derma dan bantuan kewangan dari pihak luar yang prihatin terhadap kebajikan anak-anak yatim miskin ini. Hal ini kerana Rumah Anak Yatim Miskin (RAYM) dikatakan sebagai sebuah institusi yang berdedikasi untuk menjaga dan membesarkan kanak-kanak yang telah kematian atau kehilangan ibu bapa (Kamath, Venkatappa, \& Sparshadeep, 2017). Namun setiap negara mempunyai pandangan dan definisi yang berbeza terhadap RAYM.

\section{Metod Kajian}

Kaedah kajian ini adalah menggunakan data sekunder iaitu hasil daripada kajian-kajian lepas iaitu melalui analisis dokumen. Dapatan-dapatan daripada kajian yang telah dikaji oleh pengkaji lepas telah dijadikan sumber untuk membincangkan isu mengenai RAYM. Data sekunder tersebut adalah terdiri daripada surat khabar, jurnal-jurnal dalam dan luar negara, buku-buku yang berkaitan dengan RAYM dan institusi jagaan kanak-kanak, majalah-majalah dan laman web dalam dan luar negara sebagai rujukan.

\section{Konsep RAYM Berdasarkan Kajian Lepas}

Di negara barat, Rumah anak yatim pertama dipanggil "orphanotropia" yang diasaskan oleh gereja katolik pada abad ke-1 untuk memberi sokongan kepada anak-anak yatim miskin (O Ayotunde, 2013). RAYM banyak ditubuhkan di negara-negara membangun (Roberts, 2016). Terdapat pelbagai definisi yang menjelaskan mengenai RAYM di setiap negara. Setiap negara mempunyai definisi yang berbeza mengenai RAYM (Wisegeek, 2003-2015). Di samping itu, rumah anak yatim adalah sebahagian daripada budaya setiap masyarakat (Reddy \& V, 2017).

Menurut O Ayotunde (2013), rumah anak yatim miskin adalah sebuah institusi yang menempatkan anak-anak yang ibu bapanya meninggal dunia atau tidak diketahui asal usulnya. Ia adalah institusi awam yang diwujudkan untuk memberi penjagaan dan perlindungan kepada anak-anak kematian ibu bapa. Ringkasnya, RAYM adalah sebuah institusi perumahan/berkediaman yang dikhaskan untuk menjaga ramai kanak-kanak (O Ayotunde, 2013). Manakala menurut The Faith to Action Initiative (2014) menyatakan bahawa RAYM adalah sebuah organisasi kediaman yang didedikasikan kepada kanak-kanak yang kematian ibu bapa atau ibu bapa yang tidak mampu menyokong kehidupan atau keperluan anak-anak mereka.

Selain itu, dalam erti kata lain, RAYM adalah sebuah institusi dan penempatan anak-anak yang penjaga biologinya mati atau sebaliknya iaitu tidak mampu atau enggan menjaga anak-anak mereka (Wisegeek, 2003-2015). Sesetengah RAYM mengupah pekerja profesional seperti jururawat, guru, dan orang lain yang terlibat dalam menjaga dan membesarkan anak-anak ini sepenuhnya di dalam RAYM. Orang lain hanya menawarkan keperluan asas seperti makanan, tempat tinggal dan pendidikan. Kanak-kanak yang dihantar ke RAYM adalah terdiri daripada kanak-kanak yang kematian ibu bapa, atau ibu bapanya masih hidup tetapi enggan atau tidak mampu untuk menjaga mereka. Kebanyakan RAYM berusaha untuk menempatkan kanak-kanak ini dalam persekitaran keluarga yang bersifat tradisional. Ini adalah kerana ianya dilihat sebagai lebih selamat dan wajar kanak-kanak ini tinggal di RAYM. 
Di samping itu, menurut Milani (2014) menyatakan bahawa rumah anak yatim adalah tempat yang merujuk kepada mana-mana institusi jagaan seperti wad hospital, taska atau rumah tumpangan di mana mereka ini tinggal bersama dalam satu kumpulan yang aksesnya terhad. Namun pada hari ini menurut Milani lagi, terma rumah anak yatim mempunyai konotasi yang negatif. Nama alternatif lain bagi rumah anak yatim adalah group homes, institusi jagaan kanak-kanak, Rumah Kanak-Kanak (RKK), pusat pemulihan dan pusat rawatan kanak-kanak.

Sesetengah RAYM dipisahkan mengikut jantina, tetapi kebanyakan penjagaan untuk kanak-kanak melibatkan kedua-dua jantina. Biasanya bangunan RAYM akan merangkumi banyak aspek yang mungkin terdapat di dalam rumah. Bilik-bilik di mana kanak-kanak tidur dan bilik-bilik lain yang berkaitan mungkin dijumpai di RAYM. Sekiranya RAYM berfungsi sebagai sekolah, maka bilik darjah juga adalah penting (Wisegeek, 2003-2015). Di samping itu, sesetengah RAYM tidak memelihara anak-anak yang melepasi usia tertentu dan boleh memindahkan mereka ke keluarga angkat atau institusi lain.

RAYM seringkali dikaitkan dengan kumpulan sukarelawan dan organisasi keagamaan. Banyak agama melihat penjagaan anak-anak yatim miskin adalah satu kewajipan. Maka RAYM yang mempunyai banyak mazhab yang berbeza adalah biasa. Walau bagaimanapun, sesetengah negara lebih suka anakanak yatim miskin berada dalam penjagaan rumah yang ditaja oleh pihak kerajaan, walaupun penjagaan rumah itu tidaklah sebaik penjagaan yang disediakan oleh organisasi keagamaan atau sukarelawan. Dalam banyak bidang, terdapat kebimbangan bahawa orang-orang asing atau orang-orang keagamaan yang menjaga anak-anak yatim miskin ini akan memberikan didikan yang salah.

Manakala di banyak tempat RAYM dianggap sebagai kemudahan penjagaan kediaman yang boleh diterima untuk kanak-kanak tanpa ibu bapa atau penjaga. Walau bagaimanapun, ia juga agak biasa untuk mencari RAYM di mana kana-kanak kurang sangat dijaga walaupun ianya dikawal dengan baik. Namun ianya dianggap tidak membahayakan kanak-kanak.

Walau bagaimanapun, menurut The Faith to Action Initiative (2014) menjelaskan bahawa RAYM dalam kajiannya adalah semua jenis jagaan berkediaman, dari kecil (15 atau kurang kanak-kanak) kepada institusi yang berskala besar. Bilangan ini diambilkira oleh semua orang untuk memandang rendah kerana banyak RAYM yang tidak didaftarkan dan kanak-kanak yang tinggal di dalamnya tidak dikira secara rasmi (The Faith to Action Initiative, 2014).

Justeru itu, Rumah Anak Yatim Miskin adalah anak yang kematian bapa atau kedua-dua ibu bapa (Awang et al., 2004), disisihkan atau tidak dapat memberikan penjagaan (UNICEF, 2008), tidak diketahui asal usulnya (Ashaalan \& Al-zeiby, 2016) dan dari keluarga miskin (Bilson \& Cox, 2007). Di samping itu, menurut (Reddy \& V, 2017) rumah anak yatim adalah sebuah institusi yang dikhaskan untuk penjagaan dan pendidikan anak-anak yatim, anak-anak yang didera, ditinggalkan dan diabaikan, contohnya seperti kanak-kanak yang ibu bapanya enggan atau tidak mampu menjaga mereka.

RAYM menyediakan perkhidmatan penginapan, makanan, pakaian (Zimmerman, 2005); penjagaan kesihatan, pendidikan dan aktiviti rekreasi (Ashaalan \& Al-zeiby, 2016); bimbingan dan kaunseling untuk memperkasakan kehidupan anak-anak yatim miskin yang tinggal di sana.

\section{RAYM dalam Konteks Malaysia}

Rumah anak yatim miskin terletak di semua negeri dan daerah negara ini. Ianya dimiliki dan diuruskan oleh kerajaan, badan bukan kerajaan, institusi keagamaan dan milik persendirian atau individu dermawan. Di Malaysia terdapat dua jenis pusat jagaan iaitu pusat jagaan berkediaman dan pusat jagaan harian. Pusat jagaan berkediaman adalah mana-mana premis di mana empat orang atau lebih diterima untuk jagaan sebagai penghuni di dalamnya, sama ada untuk upah atau selainnya dan seseorang yang merupakan saudara kepada pengurus premis itu tidak boleh dikira dalam menentukan bilangan orang yang diterima untuk jagaan (Undang-Undang Malaysia, 2006). 
Manakala pusat jagaan harian adalah mana-mana premis yang menempatkan empat orang atau lebih diterima untuk jagaan selama suatu tempoh berterusan yang melebihi tiga jam sehari antara matahari terbit hingga matahari terbenam, dan sekurang-kurangnya tiga hari seminggu, sama ada upah atau selainya; seseorang yang merupakan saudara kepada pengurus premis tidak boleh dikira dalam menentukan bilangan orang yang diterima sebagai penghuni (Undang-Undang Malaysia, 2006). Sehubungan itu, saudara dalam konteks ini adalah penjaga di sisi undang-undang bagi individu berkenaan, atau seseorang yang mempunyai pertalian darah, persemendaan atau pengangkatan di sisi undang-undang seperti bapa, ibu, anak, adik, abang, kakak, datuk, nenek, bapa saudara, ibu saudara atau anak saudara (Undang-Undang Malaysia, 2006).

Dalam konsep RAYM, ianya tergolong dalam pusat jagaan berkediaman kerana institusi ini menawarkan perkhidmatan penjagaan dan perlindungan kepada anak-anak yatim miskin. Pusat jagaan harian juga menawarkan khidmat jagaan dan perlindungan juga, tetapi mereka tidak tinggal di institusi tersebut 24 jam. Dahulu, RAYM adalah menempatkan anak-anak yatim di situ, namun pada hari ini, terdapat institusi lain juga yang menawarkan khidmat penjagaan dan perlindungan kepada anak-anak yatim miskin seperti pondok, madrasah dan juga pusat-pusat tahfiz. Oleh yang demikian, institusi ini boleh dikategorikan sebagai RAYM kerana mereka memberi perlindungan dan penjagaan kepada anakanak yatim miskin selain kanak-kanak yang lain.

Di Malaysia, umur kanak-kanak yang tinggal di RAYM adalah berumur antara 7-18 tahun. Namun di barat RAYM mereka menempatkan juga kanak-kanak yang berumur 0-6 tahun. Di Malaysia, kanakkanak yang berumur 0-6 tahun ini berada dibawah jagaan dan perlindungan Jabatan Kebajikan Masyarakat. Antara institusi yang bertanggungjawab menjaga dan melindungi anak-anak yatim yang berumur 0-6 tahun ini adalah seperti Rumah Kanak-kanak, Taman Sinar Harapan dan Pusat Jagaan Kanak-Kanak.

Selain memberi perkhidmatan perlindungan dan penjagaan, RAYM juga menyediakan perkhidmatan pendidikan kepada anak-anak yatim miskin. Ini bermaksud, kanak-kanak bersekolah di tempat yang sama mereka tunggal seperti pondok, tahfiz dan madrasah. Pembinaan RAYM mempunyai beberapa tujuan iaitu memelihara, mendidik dan mengasuh anak-anak yatim miskin; memilik, memaju dan mentadbir RAYM serta harta-harta kepunyaan amanah anak-anak yatim miskin dan menggalakkan kerja-kerja kebajikan di kalangan ahli dan orang ramai (Rahyl Mahyuddin, Sharifah Md Nor, Azizah Abdul Rahman, Kamariah Abu Bakar, Habibah Elias, 1993). Jika kanak-kanak ini tiada saudara mara untuk menyokong kehidupan mereka, maka RAYM adalah salah satu tempat yang akan menyediakan kanak-kanak ini perlindungan, penjagaan kesihatan, makanan, pendidikan dan penginapan (Akram, Anjum, \& Akram, 2015).

Kesimpulan, Maka penggunaan RAYM dalam artikel ini adalah bermaksud sebuah institusi jagaan yang memberi perlindungaan dan penjagaan kepada anak-anak yatim miskin di Malaysia. Hal ini kerana di Malaysia, TASKA dan TADIKA juga merupakan institusi jagaan bagi kanak-kanak. Maka untuk memberi penjelasan yang lebih jelas mengenai RAYM adalah institusi yang memberi perlindungan dan penjagaan kepada anak-anak yatim miskin.

Maka dapat disimpulan bahawa kanak-kanak yang tinggal di RAYM adalah seorang kanak-kanak yang kematian ibu atau bapa atau kedua-duanya sekali, disisihkan oleh ibu bapa, penjaga atau keluarga, keluarga miskin, tidak diketahui asal usulnya dan kelainan upaya.

\section{Kesimpulan}

Usaha menempatkan anak-anak yatim miskin di RAYM adalah satu usaha yang amat murni. Oleh itu pertumbuhan dan perkembangan anak-anak yatim miskin ini sama ada dari segi fizikal, mental mahupun rohani perlulah diberi perhatian yang sebaik mungkin sebagaimana anak-anak yang sebaya dengan mereka dalam mengecapi kehidupan di dalam keluarga sendiri. Dengan adanya RAYM ini dapat mengurangkan beban kerajaan dalam menjaga dan melindungi anak-anak yatim miskin ini daripada dibelenggu kemiskinan atau masalah-masalah sosial. 
Malaysian Journal of Social Sciences and Humanities (MJSSH), Volume 5, Issue 1, (page 40 - 45), 2020

\section{Rujukan}

Ashaalan, L., \& Al-zeiby, I. (2016). Methods Of Care For Children Living In Orphanages In Saudi Arabia (An Exploratory Field Study). Journal of International Education Research (JIER). https://doi.org/10.19030/jier.v11i1.9095

Akram, M., Anjum, F., \& Akram, N. (2015). Role of Orphanages to Uplift the Socio-Economic Status of Orphans Focusing on SOS Children's Villages in Punjab, Pakistan. Mediterranean Journal of Social Sciences, Vol 6, No 3, 177-182.

Awang, A., Sayuti, R., Jamaluddin, Z., \& Chong, C. C. (2004). Simposium Kebangsaan Kebajikan Kanak-Kanak 2004. Kepentingan Terbaik kanak-kanak: Isu \& Cabaran. Permasalahan Anak Yatim Di Institusi Kebajikan Anak Yatim.

Bani Ismail, L., Hindawi, H., Awamleh, W., \& Alawamleh, M. (2018). The key to successful management of child care centres in Jordan. International Journal of Child Care and Education Policy. https://doi.org/10.1186/s40723-018- 0042-5.

Bilson, A. \& Cox, P. (2007). Caring about Poverty. Journal of Children and Poverty, 13(1),pp.3749.Retrievedfrom:http://www.bettercarenetwork.org/BCN/details.asp?id=20556\&the meID=1002\& topi c ID=1017.

Fulcher, L. \& Faizah Mas'ud (2000). Residential child and youth care in Malaysia. Jurnal Kebajikan Masyarakat, 22(2).

Kamath, S. M., Venkatappa, K. G., \& Sparshadeep, E. M. (2017). Impact of nutritional status on cognition in institutionalized orphans: A pilot study. Journal of Clinical and Diagnostic Research. https://doi.org/10.7860/JCDR/2017/22181.9383.

Milani, N. S., Salim, A. S. B. S., \& Ujang, N. B. (2013). Spatial Privacy On Institutions For Unaccompanied Teenage Girls In Mashhad-Iran. E-BANGI.

Monasch, R., \& Boerma, J. T. (2004). Orphanhood and childcare patterns in sub-Saharan Africa: An analysis of national surveys from 40 countries. In AIDS. https://doi.org/10.1097/00002030200406003-00011.

Rahyl Mahyuddin, Sharifah Md Nor, Azizah Abdul Rahman, Kamariah Abu Bakar, Habibah Elias (1993). Budaya kerja di rumah anak yatim. Dalam Wan Rafaei Abdul Rahman, Habibah Elias dan Malini Ratnasingam (eds). Psikologi dan Budaya Kerja di Malaysia. Prosiding Persidangan Psikologi Malaysia ke-3. Bangi: Persatuan Psikologi Malaysia.

O Ayotunde, E. (2013). Evaluation of Support Facilities for Institutionalized Orphans in Nigeria. International Journal of Current Research, Vol, 5, 1049-1053.

Pinheiro, P. (2006). World Report on Violence Against Children. Geneva. United Nations. Op cit.

Reddy, M., \& V, R. (2017). Morbidity profile of children residing in orphanages - A crosssectional study in Chitradurga, Karnataka. International Journal of Medical Science and Public Health.https://doi.org/10.5455/ijmsph.2017.0409524042017

Roberts, P. (2016). Institutional Care for Children in Trinidad and Tobago: Towards a New Model od Care for Developing Countries. PhD Tesis, Faculty of Graduate Studies, University of Manitoba.

Salifu Yendork, J., \& Somhlaba, N. Z. (2014). Stress, coping and quality of life: An exploratory study of the psychological well-being of Ghanaian orphans placed in orphanages. Children and Youth Services Review. https://doi.org/10.1016/j.childyouth.2014.07.025.

The Faith to Action Initiative. (2014). Children, Orphanages, And Families: A Summary Of Research To Help Guide Faith-Based Action. Dipetik daripada http://www.faithtoaction.org/wpcontent/uploads/2014/03/Faith2Action_Resear chGui de_V9_WEB.pdf.

Undang-Undang Malaysia. (2006). Akta 506: Akta Pusat Jagaan 1993.

UNICEF. (2008). [Online] Available: http://www.unicef.org/media/media_45279.html.

UNICEF Regional Office for CEE/CIS (2010). At Home or In a Home? Formal Care and Adoption of Children in Eastern Europe and Central Asia. Retrieved from: http://www.bettercarenetwork.org/BCN/details.asp?id=25427\&themeID=1002\&t opicI $\mathrm{D}=1017$

UNICEF. (2015). Statement. Dipetik daripada; http://www.unicef.org/media/media_45277.html. Wisegeek. (2003-2015). [Online] Available: http://www.wisegeek.com/what-is-an- orphanage.htm\# Copyright $\odot 2003$ - 2015 Conjecture Corporation. 
Malaysian Journal of Social Sciences and Humanities (MJSSH), Volume 5, Issue 1, (page 40 - 45), 2020

DOI: https://doi.org/10.47405/mjssh.v5i1.342

Zimmerman, B. (2005). Orphan living situations in Malawi: A comparison of orphanages and foster homes. Review of Policy Research. https://doi.org/10.1111/j.1541-1338.2005.00180.x 